


\title{
A diffractometer project for Brazilian Multipurpose Reactor (RMB): McStas simulations and instrument optimization
}

Souza $^{a}$ A.P.S., de Oliveira ${ }^{a}$ L.P., Yokaichiya ${ }^{b}$., Genezini ${ }^{a}$ F.A., Franco ${ }^{a}$ M.K.K.D.

${ }^{a}$ Instituto de Pesquisas Energéticas e Nucleares (IPEN/CNEN) Reator Multipróposito Brasileiro(RMB), 05508-000,

São Paulo, São Paulo, Brazil

alexandre.souza@ipen.br

${ }^{b}$ Universidade Federal do Paraná, Departamento de Física, 80060-000, Curitiba, Paraná, Brazil

\begin{abstract}
The high-resolution diffractometer is one of the first instruments of the set of $\mathbf{1 5}$ priority neutron scattering instruments to be installed at the Brazilian Multipurpose Reactor (RMB). A basic project of this instrument consists of the existence of three guides through which neutrons pass from source to sample to guarantee maximum neutron flux at the sample position. In this study, we investigate guide geometry performance considering fixed diffractometer geometry and spatial arrangement. Comparisons between different guide shapes and supermirrors are performed using software based on the Monte Carlo method, McStas. Our conclusion shows that a better solution is splitting the initial flux into two different guides to obtain the maximum flux at the sample position.
\end{abstract}

Keywords: diffractometer, McStas simulations, neutron flux. 


\section{INTRODUCTION}

The upcoming Brazilian Multipurpose Reactor (RMB) is a new facility designed for radioisotope production and neutron-beam research [1]. The diffraction technique is very important and well established for our understanding of the solid-state of matter and consequently is one of the priorities of RMB instruments. There are some advantages to studying structures at the atomic scale with neutrons. They are particles that have spin $1 / 2$ and no electric charge. Thus, their interactions mainly occur with other atom nuclei instead of electrons as in X-ray interaction. Since neutrons possess the magnetic moment, they are scattered electrons of atoms with resultant magnetic moments. So, they can be used to investigate materials with ferromagnetic and antiferromagnetic properties, for instance. Besides, the neutron-nuclei interaction, which occurs in neutron diffraction, allows different interactions with Periodic Table elements than X-Ray diffraction. Also, such neutron-nuclei interaction fits well in studying light atoms in the presence of heavy ones, which makes both complementary techniques. $[2,3]$.

Neutron instruments are generally expensive and require a previous study of components and performance before being installed or built. In this spirit, McStas software is an available tool frequently used to simulate neutron instruments for reactors and spallation facilities $[4,5]$. It provides components to construct virtual instruments and it uses the Monte Carlo method to produce neutron beams to verify their performance.

In 2010, there was a bilateral agreement between Brazil and Argentina Governments that stipulates the conceptual model of the Australian research reactor OPAL as a base for their new reactors, i.e., RMB and RA10, respectively [6]. On the other hand, OPAL, namely the Open-pool Australian Lightwater reactor, is a state-of-the-art multi-purpose and 20MW reactor that was built by the Argentinian technology company INVAP [7]. According to the 2010 agreement, the same Argentinian company, INVAP, was set to be responsible for the RMB and RA10 projects [8].

Since the RMB has in OPAL its reference reactor, we consider it plausible to use a powder diffractometer of this facility, called Echidna, as a first approach of the project. According to literature, and Echidna's available information, we build a basic diffractometer that mimics OPAL's 
instrument $[9,10]$. Even though instrument design is defined, we need to define the initial neutron flux profile to perform simulations and test RMB diffractometer performance.

An available and accurate way to describe the neutron flux produced by a reactor core is through the Monte Carlo simulations. In the RMB project, they were carried out by using MCNP codes, but other software programs are available according to literature. These simulations are normally complex and take long computational time and/or powerful computers to be performed.

Nevertheless, there are simplified tools that allow us to reproduce some spectra and intensity aspects of such fluxes without losing computational time and with no need for a detailed specification of the reactor core. Inside the McStas library, some components can reproduce virtual reactor sources based on Maxwellian distributions depending on reactor temperature and neutron production. Another way to circumvent core simulations during instruments and guides simulations consists of saving simulated neutrons in a file to be used later. The McStas also possess a component that reads the MCNP outputs and converts them into sources to study other optical instruments, e.g., guides, mirrors, benders, collimators, crystals, etc.

For this first approach to instrument performance, we choose these two different types of source input, since RMB core MCNP output is still not available. Further analysis using RMB proper neutron flux input is let for future studies considering present simulation results.

In this present scenario, we perform simulations considering a standard diffractometer based on Echidna and with sources produced by components Source_gen( ) and Virtual_mcnp_input( ) [11]. Here, we compare results from Institut Laue-Langevin (ILL) thermal source, which is described by a Maxwellian profile distribution and produced by the component Source_gen( ) [12], and IEA- R1 source, which corresponds to a neutron flux input file read by the component Virtual_mcnp_input( ) and previously obtained via MCNP simulations [13].

The way to connect any source to an instrument is a crucial task to distribute available flux properly. An interesting example occurs at OPAL, where the Echidna monochromator neutron flux comes from the Wombat high-intensity diffractometer by the same guide [10]. Then, the uses and delivering definition of available neutron flux (neutron guides definition) to any instrument is necessary to avoid losing performance and optimize the neutron transportation system. 
In this study, we intend to investigate those guide configurations that provide maximum flux at the sample position. We focus on simulating a basic diffractometer configuration inspired on Echidna with different neutron guide systems (different guide length and supermirrors) to identify worthwhile scenarios. In the next section, we describe the diffraction technique, McStas simulations, and virtual diffractometer components. The last section contains the final remarks and conclusions. Aspects as guide coating, configuration, and geometry are valuable for defining the RMB guide system and instrument arrangement in future works.

\section{DIFFRACTION TECHNIQUE AND MCSTAS SIMULATIONS}

The powder high-resolution diffractometer combined with the Rietveld refinement method is applied in distinguishing different Bragg peaks, which is necessary for material structure and sample phases determination $[14,15]$. In such a scenario, any optimization consists of increasing resolution with no expense of intensity. There are a lot of studies in the literature that discuss many aspects of diffractometer in order to achieve fine resolution without losing intensity or to try to increase intensity in real facilities high-resolution instruments $[16,17,18,19]$.

The paper of Caglioti and collaborators is a milestone in a diffractometer setting and optimization [20]. Consequently, current instrument optimizations have in Caglioti's assembly the first step to obtain a fine resolution. In short, almost all modifications in components of the Caglioti diffractometer are based on instrument geometry and the use of horizontal or vertical focusing monochromator. Vertical focusing is an example of a process that allows a gain factor between 2 and 10 at the sample position with no change in instrument resolution [21].

However, before analyzing collimator and monochromator properties it is necessary to guarantee a maximum flux delivery to the sample position. Consequently, we decide to first ensure guide system efficiency before studying instrument optimization like geometry, components, and samples.

The diffractometer configuration is shown in Figure 1. Transportation components of simulations consist of a funnel guide, main guide, and secondary guide that is between monochromator and sample position. Other McStas components form a simple version of the Echidna high-resolution diffractometer. Such an instrument has a vertical focusing monochromator [14, 15]. Collimation is 
provided by a primary Soller collimator, a secondary Soller collimator, a radial collimator, which follows the Caglioti fundamental configuration [20, 22]. The Neutron flux source consists, as already mentioned, of two different kinds of McStas components, namely Source_gen( ) and Virtual_mcnp_input( ), which correspond in present simulations on an ILL thermal source and the IEA$\mathrm{R} 1 \mathrm{BH} 3$ source.

Figure 1: A top-view sketch of simulated diffractometer with a close spotlight on both guide connection. The diffractometer consists of a Caglioti assemble with primary, secondary, and radial collimators, monochromator, sample, and radial detector. The guide system is composed sequentially by a Neutron flux source (virtual or MCNP McStas source), a funnel and main guides, and a secondary guide between monochromator and secondary collimator.

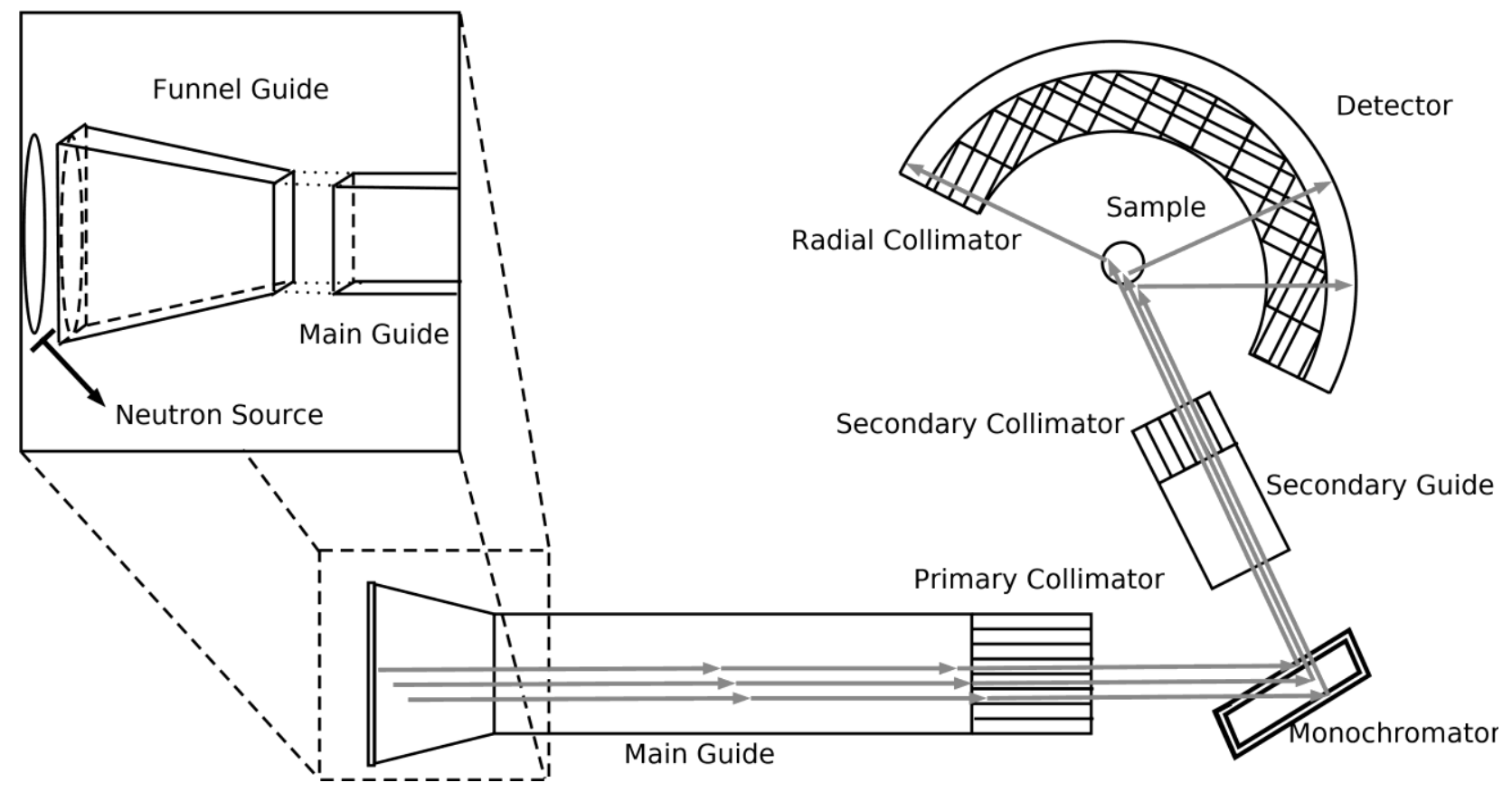

Input values of McStas simulation components are described in Tables 1 and 2. In Table 1, we present fixed values of monochromator height $(\mathrm{h})$ and mosaicity $(\beta)$, takeoff angle $\left(\theta_{\mathrm{M}}\right)$, reflected wavelength $(\lambda)$ and collimation primary, secondary and radial divergence $\left(\alpha_{1}, \alpha_{2}\right.$ and $\alpha_{3}$, respectively). Notwithstanding, these fixed values correspond to real parameters of the Echidna highresolution diffractometer $[9,10]$. On the other hand, Table 2 contains simulation cases a different funnel and main guide lengths $\left(\mathrm{L}_{\mathrm{FG}}\right.$ and $\mathrm{L}_{\mathrm{MG}}$, respectively) and supermirrors ( $\mathrm{m}$ value, where 
$\mathrm{m} \theta_{\mathrm{c}}^{\mathrm{Ni}}$ is the critical angle of supermirror and $\theta_{\mathrm{c}}^{\mathrm{Ni}}$ is the critical angle of reflection of $\mathrm{Ni}^{58}$ ). It is worth noting that values of guide length already include collimator length, namely $70 \mathrm{~cm}$ for primary collimator and $30 \mathrm{~cm}$ for secondary collimator.

The source that was obtained by MCNP code consists of simulations of the IEA-R1 Brazilian reactor at the Instituto de Pesquisas Energéticas e Nucleares - IPEN. This profile corresponds to Beam Hole Number 3 (BH3) flux and was used previously for Boron Neutron Capture Therapy (BNCT) facility shielding simulations and further studies [23, 24]. The IEA-R1 source mimics the real flux of the Brazilian reactor and consequently possesses the reactor geometry and the beam hole aperture. In this scenario, neutrons are being produced in a circular area with a radius of about $8.5 \mathrm{~cm}$.

Therefore, we standardize the ILL simulations with this same source area of IEA-R1 simulations and both source simulations types, i.e., for IEA-R1 and ILL, are performed with the same neutron transportation system, which is based on thermal guide dimensions of TG1, where Echidna is located at OPAL. Thus, the main guide has $5 \mathrm{~cm}$ width and $30 \mathrm{~cm}$ height with the variable length depending on the simulation case, as described in Table 2. Since the source area $(16.8 \times 16.8$ $\left.\mathrm{cm}^{2}\right)$ is larger than the guide entrance $\left(30 \times 5 \mathrm{~cm}^{2}\right)$, we propose a funnel guide to concentrate neutron flux into the main guide in an attempt to use all available neutrons. In this assembly, funnel guides are designed to have $16.8 \mathrm{~cm}$ width and $16.8 \mathrm{~cm}$ height at the guide entry and $5 \mathrm{~cm}$ width and $30 \mathrm{~cm}$ height at the guide exit, where it connects itself with the main guide, as shown in Figure 1.

Divergence of neutron source and supermirrors is important to determine the fraction of initial flux that reaches the sample. Besides, the simulation results of Table $\underline{2}$ allow us to define guides. Within such results, we can decide if it is worth to split source flux between two or three guides to supply neutron flux for different instruments or to keep just a single guide to feed one or two instruments (like in TG1 at OPAL). Gilles et al. found that a secondary guide between monochromator and sample position deteriorate profile quality [25]. Here we also propose to check if this secondary guide is important to keep flux at the sample position. In this sense, initial cases of Table 2 were proposed to investigate this role of secondary guide. There are sets of configurations that possess the same guide lengths, but with different values of supermirror index m. By analyzing these configurations, we can test the guide performance. In this scenario, we observe that guides with $m=0$ correspond to no guide configurations since surfaces absorb all incident neutrons. 
Table 1: Simulation technical data of diffractometer. The fixed value parameters consist of monochromator slab number, mosaicity $(\beta)$ and height $(\mathrm{h})$, takeoff angle $\left(\theta_{\mathrm{M}}\right)$, main diffracted wavelength $(\lambda)$ and primary, secondary and radial collimator divergences $\left(\alpha_{1}, \alpha_{2}\right.$ and $\alpha_{3}$,

Components and respectively)

\begin{tabular}{cc}
\hline $\begin{array}{c}\text { Components and } \\
\text { Instrument } \\
\text { Characteristics }\end{array}$ & Adopted Values \\
\hline Monochromator & $\beta=33^{\prime}$ \\
& $\mathrm{h}=300 \mathrm{~mm}$ \\
Takeoff Angle & $\theta_{\mathrm{M}}=140^{\circ}$ \\
Wavelength & $\lambda^{\circ}=1.62 \AA$ \\
& $\alpha_{1}=10^{\prime}$ \\
Collimation & $\alpha_{2}=10^{\prime}$ \\
& $\alpha_{3}=5$ \\
\hline
\end{tabular}

The simulated monochromator was constructed based on literature, where a vertical focusing monochromator is provided by a curved assembly of monocrystal wafers also known as a finger. Its curvature is linked to diffractometer geometry by the following equation:

$$
\frac{1}{R_{v}}=\frac{1}{2 \sin \theta_{M}}\left(\frac{1}{L_{1}}+\frac{1}{L_{2}}\right)
$$

where $\mathrm{Rv}$ is monochromator curvature radius, $\theta_{\mathrm{M}}$ is takeoff angle, $\mathrm{L}_{1}=\mathrm{L}_{\mathrm{FG}}+\mathrm{L}_{\mathrm{MG}}$ and $\mathrm{L}_{2}$ is the monochromator-sample distance [25]. Following this relation, we ensure maximum flux at the sample position. However, there are in literature other ways to maximize incoming flux in the curved detector besides monochromator vertical focusing. Horizontal focusing monochromator and sample size adjustment are available possibilities, which are let to be analyzed in detail in future studies [25, 26].

Inside simulation McStas codes, we have placed four virtual detectors between the main components of the diffractometer to study flux behavior through different proposed guide systems. 
These virtual detectors are described by component Monitor_nD( ) and do not interfere with neutron flux, but only check neutron flux, i.e., neutrons per square centimeter per second $\left(n / \mathrm{cm}^{2} s\right)$ [11]. They are settled up between the source and the guide entrance, the primary collimator and the monochromator, the monochromator and the secondary guide entrance, and between the secondary collimator and the sample position. These four detectors are positioned exactly after source, primary collimator, monochromator, and secondary collimator and for this reason, they possess the same areas of these component neutron exits, i.e., $16.8 \times 16.8,30 \times 5,30 \times 5$ and $12.8 \times 5 \mathrm{~cm}^{2}$, respectively. It is worth noting that the detector area after the secondary collimator is smaller due to the focusing process imposed on neutron flux by the monochromator.

Table 2: McStas simulation cases that are defined for different combinations of funnel guide length $\left(L_{F G}\right)$, main guide length $\left(L_{M G}\right)$, and supermirror coating index $(m)$. Letters $A$ and $B$ in the case label stand for simulations with the IEA-RI and the ILL source, respectively.

\begin{tabular}{cccc}
\hline Simulation & $\mathbf{L}_{\mathbf{F G}}(\mathbf{m})$ & $\mathbf{L}_{\mathbf{M G}}(\mathbf{m})$ & $\mathbf{m}$ \\
\hline $1(\mathrm{~A} / \mathrm{B})$ & $\varnothing$ & $\varnothing$ & $\varnothing$ \\
$2(\mathrm{~A} / \mathrm{B})$ & 58 & 0 & 0 \\
$3(\mathrm{~A} / \mathrm{B})$ & 58 & 0 & 1 \\
$4(\mathrm{~A} / \mathrm{B})$ & 58 & 0 & 2 \\
$5(\mathrm{~A} / \mathrm{B})$ & 58 & 0 & 3 \\
$6(\mathrm{~A} / \mathrm{B})$ & 0 & 58 & 0 \\
$7(\mathrm{~A} / \mathrm{B})$ & 0 & 58 & 1 \\
$8(\mathrm{~A} / \mathrm{B})$ & 0 & 58 & 2 \\
$9(\mathrm{~A} / \mathrm{B})$ & 0 & 58 & 3 \\
$10(\mathrm{~A} / \mathrm{B})$ & 3 & 55 & 2 \\
$11(\mathrm{~A} / \mathrm{B})$ & 3 & 5 & 2 \\
$12(\mathrm{~A} / \mathrm{B})$ & 5 & 5 & 2 \\
$13(\mathrm{~A} / \mathrm{B})$ & 10 & 5 & 2 \\
$14(\mathrm{~A} / \mathrm{B})$ & 15 & 5 & 2 \\
\hline
\end{tabular}

In these terms, each detector returns flux values for all simulations, and this data is presented in Tables 3 and 4 . The fluxes of these detectors are represented namely by variables $F_{S}, F_{C 1}, F_{M}$, 
and $\mathrm{F}_{\mathrm{C} 2}$, which correspond to detectors after the source, the primary collimator, the monochromator, and the secondary collimator, respectively. All proposed simulations are shown in Table 2, they were carried out through McStas codes with $10^{8}$ neutron rays and final flux values were analyzed. Results for IEA-R1 and ILL simulations, which are labeled respectively with letters A and B, are presented in Tables 3 and 4, respectively and each column corresponds to a specific detector neutron flux.

Here we focus on comparing flux values of source and primary collimator and also monochromator and sample since monochromator parameters were fixed during simulations. After comparing fluxes of the source (first column) and primary collimator (second column) for different supermirrors in Table 3, we observe, as expected, a continuous increase of incoming flux at monochromator according to $\mathrm{m}$ values (from $\mathrm{m}=0$ to $\mathrm{m}=3$ ). Besides, simulations $1 \mathrm{~A}$ and $1 \mathrm{~B}$ in Table 2 correspond to cases with no guides $(\varnothing)$ and a distance of $8 \mathrm{~m}$ between source and primary collimator, and as already indicated, they are used to investigate secondary guide role in saving neutron flux between monochromator and sample.

We verify cases where there is an enhance in flux between monochromator and sample due to monochromator focusing. In other words, the neutron stream is passing throw a smaller area in the sample position than in the monochromator without losing many neutrons. According to the results (last column of Tables 3 and 4) and considering that the monochromator area is about $60 \%$ larger than the detector area at the sample position, it is possible to guarantee that there are no significant neutron flux loss corresponding to secondary guide. In Table 3, the minimum loss is about $10 \%$ (simulation 7A), and a maximum of about $60 \%$ (simulation 14A).

There is another interesting result in Table 3. By checking simulations $1 \mathrm{~A}$ and $11 \mathrm{~A}$, we observe that both fluxes after primary collimator $\left(F_{C 1}\right)$ do not vary more than $2 \%$. This happens because distances with and without guides are equivalent $(8 \mathrm{~m})$. This result shows, at least for this diffractometer assembly, that for short distances the use of the guide is not crucial. This justifies the use of beam tubes instead of neutron guides in facilities where thermal neutron instruments are located near to reactor face like in $\mathrm{HZB}$, for instance. 
Table 3: Simulation Results with IEA-R1 Source.

\begin{tabular}{|c|c|c|c|c|c|}
\hline \multicolumn{2}{|c|}{ Source: } & \multicolumn{4}{|c|}{ IEA-R1 } \\
\hline \multirow{4}{*}{$\begin{array}{l}\text { Simulation } \\
\text { Case }\end{array}$} & & \multicolumn{3}{|c|}{ Neutron Flux Detection } & \multirow[b]{2}{*}{$\begin{array}{c}\text { Secondary Collimator } \\
\text { (Sample) }\end{array}$} \\
\hline & $\begin{array}{l}\text { Detector } \\
\text { Position: }\end{array}$ & Source & Primary Collimator & Monochromator & \\
\hline & $\begin{array}{c}\text { Detector } \\
\text { Area }\left(\mathrm{cm}^{2}\right):\end{array}$ & $16.8 \times 16.8$ & $30 \times 5$ & $30 \times 5$ & $12.8 \times 5$ \\
\hline & $m$ & $F_{S}\left(\times 10^{11} \mathrm{n} / \mathrm{cm}^{2} \mathrm{~s}\right)$ & $F_{C 1}\left(\times 10^{7} \mathrm{n} / \mathrm{cm}^{2} \mathrm{~s}\right)$ & $F_{M}\left(\times 10^{6} \mathrm{n} / \mathrm{cm}^{2} \mathrm{~s}\right)$ & $F_{C 2}\left(\times 10^{6} \mathrm{n} / \mathrm{cm}^{2} \mathrm{~s}\right)$ \\
\hline $1 \mathrm{~A}$ & $\varnothing$ & 2.504 & 40.75 & 34.10 & 30.57 \\
\hline $2 \mathrm{~A}$ & 0 & 2.504 & 6.912 & 1.628 & 2.536 \\
\hline $\mathbf{3 A}$ & 1 & 2.504 & 9.766 & 1.731 & 2.677 \\
\hline 4A & 2 & 2.504 & 13.89 & 1.792 & 2.747 \\
\hline $5 \mathbf{A}$ & 3 & 2.504 & 16.19 & 1.834 & 2.715 \\
\hline 6A & 0 & 2.504 & 7.034 & 1.752 & 2.860 \\
\hline 7A & 1 & 2.504 & 8.675 & 1.078 & 2.306 \\
\hline $\mathbf{8 A}$ & 2 & 2.504 & 12.54 & 1.132 & 2.133 \\
\hline 9A & 3 & 2.504 & 16.05 & 1.138 & 2.131 \\
\hline $\mathbf{1 0 A}$ & 2 & 2.504 & 12.67 & 1.165 & 2.211 \\
\hline 11A & 2 & 2.504 & 39.99 & 31.54 & 27.96 \\
\hline $12 \mathrm{~A}$ & 2 & 2.504 & 34.08 & 24.44 & 23.36 \\
\hline 13A & 2 & 2.504 & 27.78 & 22.55 & 19.62 \\
\hline $14 \mathrm{~A}$ & 2 & 2.504 & 23.73 & 18.20 & 17.76 \\
\hline
\end{tabular}


Table 4: Simulation Results with ILL Source

\begin{tabular}{|c|c|c|c|c|c|}
\hline \multicolumn{2}{|c|}{ Source: } & \multicolumn{4}{|c|}{ ILL } \\
\hline \multirow{4}{*}{$\begin{array}{l}\text { Simulation } \\
\text { Case }\end{array}$} & \multicolumn{5}{|c|}{ Neutron Flux Detection } \\
\hline & $\begin{array}{l}\text { Detector } \\
\text { Position: }\end{array}$ & Source & Primary Collimator & Monochromator & $\begin{array}{c}\text { Secondary Collimator } \\
\text { (Sample) }\end{array}$ \\
\hline & $\begin{array}{c}\text { Detector } \\
\text { Area }\left(\mathrm{cm}^{2}\right):\end{array}$ & $16.8 \times 16.8$ & $30 \times 5$ & $30 \times 5$ & $12.8 \times 5$ \\
\hline & $m$ & $F_{S}\left(\times 10^{8} \mathrm{n} / \mathrm{cm}^{2} \mathrm{~s}\right)$ & $F_{C 1}\left(\times 10^{\prime} \mathrm{n} / \mathrm{cm}^{2} \mathrm{~s}\right)$ & $F_{M}\left(\times 10^{5} \mathrm{n} / \mathrm{cm}^{2} \mathrm{~s}\right)$ & $F_{C 2}\left(\times 10^{4} \mathrm{n} / \mathrm{cm}^{2} \mathrm{~s}\right)$ \\
\hline 1B & $\varnothing$ & 133.0 & 115.7 & 32.60 & 111.0 \\
\hline 2B & 0 & 2.106 & 9.605 & 2.491 & 7.712 \\
\hline 3B & 1 & 2.107 & 11.61 & 3.083 & 9.791 \\
\hline 4B & 2 & 2.108 & 11.67 & 3.216 & 10.98 \\
\hline 5B & 3 & 2.107 & 11.67 & 3.223 & 10.91 \\
\hline 6B & 0 & 2.159 & 9.258 & 2.554 & 8.512 \\
\hline $7 B$ & 1 & 2.159 & 10.84 & 2.942 & 10.01 \\
\hline 8B & 2 & 2.158 & 11.02 & 2.994 & 10.13 \\
\hline 9B & 3 & 2.159 & 11.02 & 3.050 & 9.489 \\
\hline 10B & 2 & 786.4 & 50.83 & 11.68 & 37.90 \\
\hline 11B & 2 & 786.3 & 180.2 & 51.25 & 169.3 \\
\hline 12B & 2 & 283.4 & 138.3 & 37.16 & 128.6 \\
\hline 13B & 2 & 70.86 & 82.66 & 22.83 & 75.38 \\
\hline 14B & 2 & 31.51 & 55.07 & 15.25 & 49.83 \\
\hline
\end{tabular}


We observe the same behavior of no use of guides when fluxes after monochromator and secondary collimator are compared, i.e., $F_{M}$ and $F_{C 2}$. The comparison of these values is slightly different from the last one because previous fluxes are not equal. That is, we have the same value of $F_{S}$ for all IEA-R1 simulations, but values of $F_{M}$ are different for cases $1 \mathrm{~A}$ and $11 \mathrm{~A}$. The way to circumvent this problem and compare each performance is to analyze neutrons per second transmission percentage instead of simply checking fluxes. In this scenario, the tax of neutrons is, for values of $F_{M}$ and $F_{C 2}, 5.115 \times 10^{8}$ and $1.956 \times 10^{7} \mathrm{n} / \mathrm{s}$ for case $1 \mathrm{~A}$, and $4.731 \times 10^{8}$ and $1.789 \times 10^{7} \mathrm{n} / \mathrm{s}$ for case 11A. By dividing both pairs of taxes, we obtain the neutron transmission efficiency of $38,25 \%$ and $37,82 \%$ for cases $1 \mathrm{~A}$ and $11 \mathrm{~A}$, respectively. From this comparison we observe that a secondary guide, at least for these cases, is not necessary, which is coherent to Gilles et. al. study [25]. We observe a similar behavior by checking such efficiency for B cases and we found that all transmissions between about $13 \%$ and $15 \%$, which also is plausible according to the work of Gilles.

On the other hand, we verify some values that are not equivalent when comparing $\mathrm{A}$ and $\mathrm{B}$ simulations. These discrepancies are noticed on all simulations with $58 \mathrm{~m}$ long guides, for the funnel or even the main guides, i.e., by comparing $2 \mathrm{~A}$ to $9 \mathrm{~A}$ cases with their correspondent configurations $2 \mathrm{~B}$ to $9 \mathrm{~B}$. We observe that values of $F_{C 1}$ for A simulations are being improved (higher fluxes) as the index $\mathrm{m}$ of supermirror coating is increasing. Here the values of $F_{C 1}$ of cases $2 \mathrm{~A}$ and $6 \mathrm{~A}$ are $42,69 \%$ and $43,82 \%$ of cases $5 \mathrm{~A}$ and $9 \mathrm{~A}$, respectively. Notwithstanding, the comparison of the same ILL cases, i.e., $2 \mathrm{~B}$ with $5 \mathrm{~B}$, and $6 \mathrm{~B}$ and $9 \mathrm{~B}$, results in $82,30 \%$ and $84,01 \%$. In addition, we observe no difference between in B simulations for using $m=2$ and $m=3$, which correspond to cases $4 \mathrm{~B}$ and $5 \mathrm{~B}$, and $8 \mathrm{~B}$ and $9 \mathrm{~B}$.

We believe that this behavior is due to an internal characteristic of McStas component Source_gen( ), which is used to produce ILL source. Such a component is efficient to reproduce intensity and wavelength profile, by not the source divergence, which has to be defined according to virtual source area and distance to guide system entrance, for instance. Then, we conclude that the IEA-R1 source possesses higher angles of divergence than the ILL source. The latter source consequently possesses a source-primary collimator distance in a way that neutrons 
have no divergence enough to hit guide walls. In these terms, define properly this distance of aim is crucial for using these virtual sources to mimic real ones.

By comparing fluxes after primary collimator (of column $F_{C 1}$ ) of simulation $2 \mathrm{~A}$ to $5 \mathrm{~A}$ with $6 \mathrm{~A}$ to $9 \mathrm{~A}$ of Table 3 and simulation $2 \mathrm{~B}$ to $5 \mathrm{~B}$ with $6 \mathrm{~B}$ to $9 \mathrm{~B}$ of Table 4 , we confirm that the use of funnel guide is not significant in flux gain. Consequently, a better way to use available neutrons is, at least to this scenario, to split the main neutron source area into two instruments. Another possible way to "save" neutron flux is by using transmitted upstream of monochromator as well as Wombat and Echidna diffractometer at OPAL [10].

The comparison of flux values of cases 10A/B and 11A/B, and 11A/B until 14A/B simply show us how flux decays according to final system length. However, such a scenario is not deeply analyzed since the RMB project contains a guide system and configurations similar to the OPAL reactor.

\section{CONCLUSION}

We verify a weak dependence on supermirror variety $(m)$ in ILL results. In this study, we propose an initial assembly of a high-resolution powder diffractometer for the RMB project. OPAL's correspondent diffractometer Echidna is taken as a very first project configuration. Initial simulations were carried out to investigate the neutron flux of this basic diffractometer. We analyze flux at four different parts of the instrument stream to compare guide performances. Initial results show that there is just a subtle variance of flux for the instrument close to the face reactor (about $8 \mathrm{~m}$ ). According to our results, we also verified that the secondary guide between monochromator and sample position is not necessary for this diffractometer configuration.

We also find that the funnel guide should be long enough to diminish the flux divergence, but results with long funnel guides $(58 \mathrm{~m})$ do not show significant variation next to normal straight guides (main guide) with the same length. In these terms, a better solution would be splitting initial flux in two different guides instead of using a funnel guide to focus and "save" neutrons from a source with a larger area than the main guide. Availing transmission neutron flux of monochromator in the same way as OPAL's Wombat and Echidna instruments is also a possibility to maximize neutron use. 
The analysis of the RMB guide system and instrument properties are still in progress. We are studying characteristics of fluxes along different sections of the system and curved guides are being taken into account to avoid epithermal neutrons and gamma rays. Our present results confirm that secondary guides are not crucial, since there is no significant flux loss when they are used or not. Besides, we observe that a long guide system, such as in the RMB project (about $58 \mathrm{~m}$ long), needs proper supermirror indexes when fluxes are not already collimated (low divergence) to increase system neutron transport efficiency. All new simulations will be performed with a proper MCNP RMB input and diffractometer elements, based on Echidna, will be maintained.

\section{ACKNOWLEDGMENT}

APSS and LPO would like to thank CNPq for financial support under grant numbers 381565/20181 and 380183/2019-6, respectively, as well as FAPESP for financial support at INAC 2019. We would like to thank Dr. Paulo De Tarso Dalledone Siqueira at CEN/IPEN, for the IEAR-1 source file and discuss on MCNP code.

\section{REFERENCES}

[1] PERROTTA, J. A.; SOARES, A. J.; GENEZINI, F. A.; SOUZA, F. A.; FRANCO, M. K. K. D.; and GRANADO, E., Future perspectives for neutron beam utilization in Brazil. Neutron News, v. 25, p. 3-5, 2014.

[2] SQUIRES, G., Neutron Diffraction. Nature, p. 5-6, 1964.

[3] BACON, G.E., X-ray and Neutron Diffraction. $1^{\text {st }}$ ed. Pergamon, 1966.

[4] LEFMANN, K. and NIELSEN, K., Mcstas, a general software package for neutron ray-tracing simulations, Neutron News, v. 10 (3), p. 20-23, 1999.

[5] WILLENDRUP, P.K. and LEFMANN, K. McStas (i): Introduction, Use, and Basic Principles for Ray-tracing Simulations. Journal of Neutron Research, v. 22, p. 1-16, 2020.

[6] PERROTTA, J.A. and SOARES, A.J., RMB: The New Brazilian Multipurpose Research Reactor, Atw International Journal Nuclear Power, v. 60, p. 30, 2015. 
[7] OPAL Multi-purpose Reactor. Available at: <https://www.ansto.gov.au/research/facilities/opalmulti-purpose-reactor>. Last accessed: 21. Oct. 2020.

[8] VILLARINO, E. and DOVAL, A., INVAP's research reactor designs, Science and Technology Nuclear Installations, v. 2011, 2011.

[9] LISS, K.D.; HUNTER, B.; HAGEN, M.; NOAKES, T. and KENNEDY, S., Echidna the new high-resolution powder diffractometer being built at opal, Physica B: Condensed Matter, v. 385386, p. 1010-1012, 2006.

[10] AVDEEV, M. and HESTER, J.R., ECHIDNA: a decade of high-resolution neutron powder diffraction at OPAL, Journal of Applied Crystallography, v. 51, p. 1597-1604, 2018.

[11] FARHI, E., WILLENDRUP, P.K. and KNUDSEN, E.B., Components and instruments from the library for McStas. Available at: <http://mcstas.org/download/components/>. Last accessed: 21. Oct. 2020.

[12] FARHI, E. and LEFMANN, K., The source_gen Component., Available at: <http://www.mcstas.org/download/components/sources/Source_gen.pure.html.> Last accessed: 21. Oct. 2020.

[13] FARHI, E., MONZAT, C., ARNERIN, R., VAN VUURE, T., CASTAN-GUERRERO, C., HENNANE, C., HARRAUD, P.A., CAMPIONI, G., OLlIVIER, J. and WILLENDRUP, P., Advanced Sources and Optical Components for the McStas Neutron Scattering Instrument Simulation Package. Journal od Neutron Research, v. 17, p. 63-74, 2014.

[14] RIETVELD, H.M., A profile refinement method for nuclear and magnetic structures,

Journal of Applied Crystallography, v. 2, p. 65-71, 1969.

[15] RIETVELD, H.M., The rietveld method, Physica Scripta, v. 89, p. 098002, 2014.

[16] BUCHSTEINER, A. and STER, N., Optimizations in angular dispersive neutron powder diffraction using divergent beam geometries, Nuclear Instruments and Methods in Physics Research Section A: Accelerators, Spectrometers, Detectors and Associated Equipment, v. 598, p. 534-541, 2009. 
[17] HOELZEL, M.; SENYSHYN, A.; JUENKE, N.; BOYSEN, H.; SCHMAHL, W. and FUESS, H., High- resolution neutron powder diffractometer SPODI at research reactor FRM II, Nuclear Instruments and Methods in Physics Research Section A: Accelerators, Spectrometers, Detectors and Associated Equipment, v. 667, p. 32-37, 2012.

[18] VAN EIJCK, L.; CUSSEN, L.D.; SYKORA, G.J.; SCHOONEVELD, E.M.; RHODES, N.J.; VAN WELL, A.A. and PAPPAS, C., Design and performance of a novel neutron powder diffractometer: PEARL at TU Delft, Journal of Applied Crystallography, v. 49, p. 1398- 1401, 2016.

[19] ZHANG, J.; XIA, Y.; ZHANG, Y.; PANG, B.; SUN, G.; LI, J.; HUANG, C.; WANG, Y.; PAN, J. and XIE, C., Performance improvement of the high resolution neutron diffractometer at CAEP with geant4 simulation, Journal of Instrumentation, v. 12, p. 10007, 2017.

[20] CAGLIOTI, G.; PAOLETTI, A. and RICCI, F., Choice of collimators for a crystal spectrometer for neutron diffraction, Nuclear Instruments, v. 3, p. 223-228, 1958.

[21] COURTOIS, P., Vertical neutron beam focusing with bent mosaic crystals, Journal of Physics: Conference Series, v. 746, p. 012005, 2016.

[22] HEWAT, A., Design for a conventional high-resolution neutron powder diffractometer,

Nuclear Instruments and Methods, v. 127, p. 361-370, 1975.

[23] SILVA, G.S. de A., COELHO, P.R.P. and SIQUEIRA, P. de T.D. Shielding design for a research facility in IEA-R1 reactor. In: INTERNATIONAL NUCLEAR ATLANTIC CONFERENCE, 2002; 13 Brazilian national meeting on reactor physics and thermal hydraulics; 6 Brazilian national meeting on nuclear applications, p. 3080, 2002

[24] SIQUEIRA, P. de T.D., YORIVAZ, H., SHORTO, J.M.B., \& CAVALIERI, T.A. Princípios e aplicações da Terapia por Captura de Nêutrons por Boro - BNCT. Revista Brasileira De Física Médica, v. 13, p. 116-121. 2019.

[25] GILlES, R.; ARTUS, G.; SAROUN, J.; BOYSEN, H. and FUESS, H., The new structure powder diffractometer at the FRM-II in garching, Physica B: Condensed Matter, v. 276-278, p. 87-88, 2000. 
[26] LECHNER, R.; WALLPACH, R.V.; GRAF, H.; KASPER, F.J. and MOKRANI, L., A monochromator with variable horizontal and vertical curvatures for focussing in real and reciprocal space, Nuclear Instruments and Methods in Physics Research Section A: Accelerators, Spectrometers, Detectors and Associated Equipment, v. 338, p. 65-70, 1994.

[27] POPOVICI, M., STOICA, A.D., HUBBARD, C.R., SPOONER, A., PRASK, H.J., GNAEUPEL-HEROLD, T.H., GEHRING, P.M. and ERWIN, R.W., Multiwafer focusing neutron monochromators and applications, Neutron Optics., v. 4509 , 2001. 